\title{
One in every 14 patients with early-stage lung cancer is not being treated!
}

\author{
Benny Weksler, MD, MBA
}

From the Division of Thoracic Surgery, University of Tennessee Health Science Center, Memphis, Tenn.

Disclosures: Author is a proctor for Intuitive Surgery, a consultant for Bard, and on a scientific advisory board for Biodesix.

Received for publication April 7, 2017; accepted for publication April 12, 2017; available ahead of print May 16, 2017.

Address for reprints: Benny Weksler, MD, MBA, Professor of Surgery and Preventive Medicine, Chief, Division of Thoracic Surgery, University of Tennessee Health Science Center, 1325 Eastmoreland Ave, Suite 460, Memphis, TN 38104 (E-mail: bweksler@uthsc.edu).

J Thorac Cardiovasc Surg 2017;154:1072-3

$0022-5223 / \$ 36.00$

Copyright (c) 2017 by The American Association for Thoracic Surgery

http://dx.doi.org/10.1016/j.jtcvs.2017.04.031

Graham is credited as the first surgeon to perform a curative surgery for lung cancer, completing a pneumonectomy on a physician from Pittsburgh. ${ }^{1}$ Since then, numerous developments in surgery and anesthesia have allowed more patients with lung cancer to receive treatment. Brunn ${ }^{2}$ is credited with the first single-stage lobectomy; however, pneumonectomy remained the standard of care of the surgical treatment of lung cancer until pleural drainage systems became available in the 1950s. The popularization of lobectomy for treatment of lung cancer then expanded the population of patients who could be treated surgically.

Many advances have increased the treatment options for patients with early-stage lung cancer, including minimally invasive surgical techniques, initially described in the $1990 \mathrm{~s}^{3}$ and popularized in the $2000 \mathrm{~s}^{4,5}$; sublobar resection, a lung-sparing surgery popularized in the mid$2000 \mathrm{~s}^{6,7}$; and stereotactic body radiation therapy (SBRT), introduced in 2003, for medically inoperable patients. ${ }^{8}$ One would hope that this increase in treatment options would decrease the number of untreated patients. In contradiction, the findings of McMurry and colleagues ${ }^{9}$ in the current issue of the Journal demonstrate a stable population of patients with early-stage lung cancer who remain untreated despite advances.

McMurry and colleagues ${ }^{9}$ used the National Cancer Database to analyze 15 years of trends in the treatment of clinical stage I lung cancer. Among the more encouraging trends identified was an increase in the percentage of patients with stage I lung cancer diagnosed, from $26 \%$ to $28 \%$. Although most patients treated surgically underwent lobectomy, the rate of lobectomy decreased from $55 \%$ to $50 \%$, and the number of patients treated with sublobar resection increased (from $12 \%$ to $17 \%$ ). Lymph node staging improved, with more lymph nodes sampled and a higher rate of upstaging after surgery. Less encouraging findings of the study were the lack of improvement in the percentage of patients not receiving any treatment for stage I lung cancer through the 15-year period and the fact that

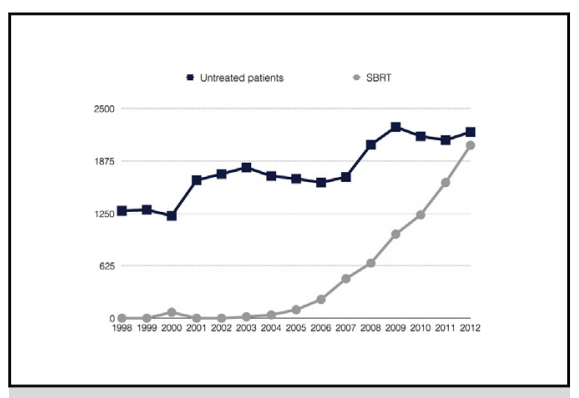

Patients with early-stage lung cancer (1998-2012): Untreated versus treated with SBRT.

\section{Central Message}

Despite advances in surgery, anesthesia, and radiation therapy, there is a sizable population of patients with potentially curable lung cancer who are not being treated.

See Article page 1080 . minorities were more likely not to receive treatment. Although the percentage of untreated patients with a Charlson comorbidity score of zero was slightly lower in the untreated group than in the surgical or SBRT groups, $57 \%$ of untreated patients had a comorbidity score of zero, suggesting that comorbidities did not limit their ability to undergo surgery or SBRT. Insurance status also does not explain the number of untreated patients, because $95.7 \%$ of untreated patients were insured by Medicare or private insurance. As outlined by McMurry and colleagues, ${ }^{9}$ this study demonstrated a sharp increase in the number of patients being treated with SBRT (from $0 \%$ to $6 \%$ ) and a decrease in patients receiving standard radiation therapy. It is surprising that SBRT did not decrease the number of patients with early-stage lung cancer who remained untreated. SBRT has been touted as an effective modality for patients with medically inoperable stage 1 lung cancer. The findings suggest that there is a small but consistent group of patients who, for unknown reasons, have not benefited from the development of less-invasive procedures to treat stage I lung cancer.

It may be encouraging to some that SBRT has not (yet) diverted many patients away from surgery for the treatment of lung cancer. In 2012, however the number of untreated patients was quite similar to the number of patients being treated with SBRT (Figure 1). For surgeons, focusing on the number of patients choosing nonsurgical treatment may obscure a more important public health problem: the 
- Untreated patients

- SBRT

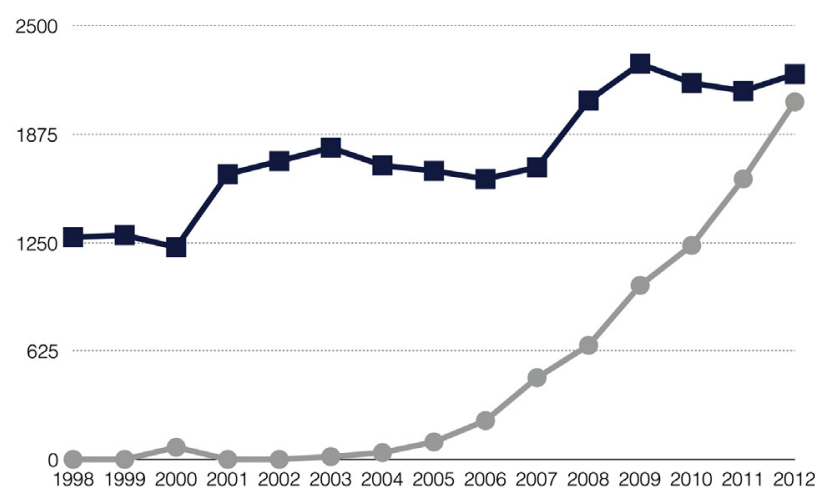

FIGURE 1. Patients with early-stage lung cancer (1998-2012): Untreated versus treated with stereotactic body radiation $(S B R T)$.

relatively sizable population of patients with potentially curable lung cancer who are not receiving any care at al. Clearly, further work is needed to understand our shortcomings in serving this population.

\section{References}

1. Graham EA, Singer JJ. Successful removal of an entire lung for carcinoma of the bronchus. JAMA. 1933;101:1371-4.

2. Brunn H. Surgical principles underlying one-stage lobectomy. Arch Surg. 1929; 18:490-515.

3. Kirby TJ, Mack MJ, Landreneau RJ, Rice TW. Initial experience with video-assisted thoracoscopic lobectomy. Ann Thorac Surg. 1993;56:1248-52; discussion 1252-3.

4. Onaitis MW, Petersen RP, Balderson SS, Toloza E, Burfeind WR, Harpole DH Jr, et al. Thoracoscopic lobectomy is a safe and versatile procedure: experience with 500 consecutive patients. Ann Surg. 2006;244:420-5.

5. McKenna RJ Jr, Houck W, Fuller CB. Video-assisted thoracic surgery lobectomy: experience with 1,100 cases. Ann Thorac Surg. 2006;81:421-5; discussion 425-6.

6. Okada M, Nishio W, Sakamoto T, Uchino K, Yuki T, Nakagawa A, et al. Effect of tumor size on prognosis in patients with non-small cell lung cancer: the role of segmentectomy as a type of lesser resection. J Thorac Cardiovasc Surg. 2005; 129:87-93.

7. El-Sherif A, Gooding WE, Santos R, Pettiford B, Ferson PF, Fernando HC, et al. Outcomes of sublobar resection versus lobectomy for stage I non-small cell lung cancer: a 13-year analysis. Ann Thorac Surg. 2006;82:408-15; discussion 415-6.

8. Fakiris AJ, McGarry RC, Yiannoutsos CT, Papiez L, Williams M, Henderson MA et al. Stereotactic body radiation therapy for early-stage non-small-cell lung carcinoma: four-year results of a prospective phase II study. Int J Radiat Oncol Biol Phys. 2009;75:677-82.

9. McMurry TL, Shah PM, Samson P, Robinson CG, Kozower BD. Treatment of stage I non-small cell lung cancer: what's trending? J Thorac Cardiovasc Surg. 2017; $154: 1080-7$ 